\title{
Clozapine Efficacy in a Case of Severe Treatment-Resistant Postpartum Psychosis
}

This article was published in the following Dove Press journal:

Risk Management and Healthcare Policy

\author{
Andreea Teodorescu' \\ Petru Ifteni $\mathbb{D}^{\prime}$ \\ Ana Dragan ${ }^{2}$ \\ Marius Alexandru Moga \\ Ana Aliana Miron' \\ Lorena Dima'
}

'Transilvania University of Brasov, Faculty of Medicine, Brasov, Romania; ${ }^{2}$ Clinical Hospital of Psychiatry and Neurology of Brasov, 3rd Department of Clinical Psychiatry, Brasov, Romania
Correspondence: Petru Ifteni Transilvania University of Brasov, Faculty of Medicine, 29th Eroilor Bvd, Brasov, Romania

Tel +40724993329

Email petru_ifteni@yahoo.com
Background: The postpartum period is a difficult time for mother and family. Unfortunately, in some cases, two psychiatric complications may occur: postpartum psychoses (PPP) with a prevalence of $0.2 \%$ and a very low incidence of $0.25-0.50$ per 1000 deliveries, and post-natal depressions with an incidence of 10 to $20 \%$ per 1000 deliveries. The onset of postpartum psychosis is in the first 4 weeks after childbirth with symptoms such as emotional lability, cognitive disorganization, delusional beliefs and hallucinations. It requires hospitalization due to the high risk of suicide and infanticide. The studies reveal that the treatment can include FGAs (first-generation antipsychotics), such as haloperidol, and SGAs (second-generation antipsychotics), such as olanzapine, quetiapine and risperidone. The literature is scarce in what resistant PPP is concerned and no such cases treated with clozapine have been reported, according to our knowledge. The present case report focuses on a female diagnosed with PPP who was treated with clozapine due to the lack of response to adequate dosage of 2 second-generation antipsychotics.

Case Presentation: We present the case of a 30-year-old primiparous woman on her 3rd day after delivery, admitted in the psychiatric emergency unit for agitation, intrusive thoughts with a content frequently related to the infant, ideas of reference, disorganized speech, bizarre behavior, verbal stereotypes, insomnia and anxiety. Due to lack of response to adequate dosage of 2 second-generation antipsychotics, clozapine was initiated up to $250 \mathrm{mg} /$ day. The symptoms remitted in the next 5 days and the patient was discharged. After discharge, at the patient's request, clozapine was replaced by olanzapine. Visit at 1 year revealed full remission of symptoms.

Conclusion: Although data is extremely limited, clozapine has been shown to be effective and safe in a severe case of treatment-resistant PPP.

Keywords: postpartum psychosis, antipsychotics, clozapine, suicide, treatment-resistant

\section{Background}

The postpartum period is a difficult time for mother and family. Unfortunately, in some cases, two psychiatric complications may occur: postpartum psychoses (PPP) with a prevalence of $0.2 \%$ and a very low incidence of $0.25-0.50$ per 1000 deliveries and post-natal depressions with an incidence of 10 to $20 \%$ per 1000 deliveries. The postpartum psychosis is not only rare, but it is also not officially recognized as a distinct disorder in DSM-5. ${ }^{1,2}$

The onset of postpartum psychosis (a psychiatric emergency) is in the first 4 weeks after childbirth; it is marked by symptoms such as emotional lability, cognitive disorganization, delusional beliefs and hallucinations and it is most likely an overt presentation of bipolar disorder. ${ }^{3}$ It requires hospitalization due to the high 
risk of suicide and infanticide. ${ }^{4}$ Infanticide is associated with imperative hallucinations that command to kill the child or delusions that the child is possessed. ${ }^{5}$

The risk of developing psychosis is higher in the first 30 days after childbirth, especially in primiparous. Women who are already vulnerable as a result of genetics or stressful environmental exposure are susceptible to mental disease in this period and this was attributed to neuro-hormonal factors. ${ }^{6}$ The levels of estrogen and oxytocin gradually rise during the pregnancy and drop sharply after delivery, returning to normal within 3 weeks. Considering that the occurrence of psychosis is associated in time with the abrupt decline of the two hormones, an increased sensitivity of dopamine receptors due to the sudden decrease in estrogen levels has been involved. Given the putative role of estradiol and oxytocin in the pathophysiology, both estrogens (sometimes associated with progesterone) and oxytocin have been tested as potential treatments for nonpsychotic and psychotic illness in the puerperium, but the results of the clinical studies available so far are inconclusive to sustain their use. ${ }^{6}$

Jones et al conducted a genome-wide linkage study in families with bipolar disorder in which at least one woman had suffered a manic or psychotic episode within 6 weeks postpartum. They reported significant linkage signal on chromosome 16p13 and a suggestive linkage signal on chromosome 8q24, which suggests that chromosome 16 and chromosome 8 may contain genes potentially involved in the predisposition to puerperal psychosis. ${ }^{7}$

The other risk factors include being unmarried, first baby, Caesarian section, perinatal death, all this under the name of psychological stress. Also, women with a history of manic or depressive episodes have a higher risk than women with schizophrenia. ${ }^{8}$ Almost $10 \%$ of women hospitalized for psychiatric morbidity before delivery develop postpartum psychosis after their first birth. ${ }^{9}$ Of all women with PPP, $70 \%$ to $90 \%$ have bipolar disorder or schizoaffective disorder, while approximately $12 \%$ have schizophrenia. ${ }^{10,11}$ The risk of non-puerperal admission is higher for women with schizophrenia and PPP is a part of a lifelong recurrent psychiatric disorder. ${ }^{12}$

Generally, the prognosis for a singular episode is favorable, with symptoms remission and good social and occupational functioning in $75-86 \%$ of the cases. However, it is considered as belonging to the bipolar spectrum, with potential recurrences ${ }^{13}$ or as a part of schizophrenia with $50 \%$ recoveries, $33 \%$ recurrent episodes and 5\% treatment-resistant schizophrenia (TRS) cases. ${ }^{14,15}$
Treatment for PPP is similar with non-puerperal episodes. The existing studies reveal that the treatment can include FGAs (first-generation antipsychotics), such as haloperidol, and SGAs (second-generation antipsychotics), such as olanzapine, quetiapine and risperidone. Olanzapine and quetiapine are preferred during breastfeeding, other antipsychotics are rarely mentioned. ${ }^{16,17}$

Regarding the association of gonadal hormones with antipsychotic use, there are still many aspects to be elucidated. While convincing evidence on their benefits is still missing, many factors should be taken into consideration. For instance, pharmacokinetic interactions of hormones with CYPP450 enzymes might change the plasma concentration of antipsychotics, thus influencing their effect on psychotic symptoms independent of the pharmacodynamics of estrogen. In this case, the outcome may depend on the antipsychotic agent; olanzapine and clozapine are metabolized by CYP1A2 liver enzyme, which is inhibited by estrogen; co-administration of estrogen will increase the antipsychotic level, while quetiapine is mainly metabolized by CYP3A4, which is induced by estrogens, so the antipsychotic level will decrease. ${ }^{6}$

The literature is very scarce in what resistant PPP is concerned and according to our knowledge no such cases treated with clozapine have been reported.

The present case report focuses on a female diagnosed with PPP who was treated with clozapine due to lack of response to adequate dosage of two SGAs. The Hospital Ethics' Committee approval was not necessary for the publication of this case report. The patient provided written consent for the anonymous publication of her case.

\section{Case Presentation}

We present the case of a 30-year-old primiparous woman, brought by her husband on day 3 postpartum and admitted in the psychiatric emergency unit for agitation, intrusive thoughts with a content frequently related to the infant, ideas of reference, disorganized speech, bizarre behavior, verbal stereotypes, insomnia and anxiety.

From her history, we noticed a previous psychotic episode at the age of 24 , successfully treated with olanzapine $10 \mathrm{mg} /$ day for 6 months and then stopped at her physician's recommendation. This episode was closely related to a stressful event. The patient had fully recovered without any residual symptoms. She got married and worked without any psychiatric problems. The biological investigations showed mild iron-deficiency anemia, mild hypercholesterolemia. The head computer tomography scan was normal. On 
admission, she was treated with injectable haloperidol $5 \mathrm{mg} /$ day, diazepam $20 \mathrm{mg}$ /day and cabergoline $1 \mathrm{mg}$ /day for two days for ablactation. Due to extrapyramidal side effects (acute dystonia and rigidity), she was switched to olanzapine $20 \mathrm{mg}$ /day, lorazepam $4 \mathrm{mg} /$ day and trihexyphenidyl 4mg/ day. Since no significant clinical response was registered after 2 weeks, the patient received add-on therapy with risperidone $4 \mathrm{mg} /$ day. Despite the combination of two potent antipsychotics administered in proper doses, the patient remained intensely psychotic and 4 points mechanical restraint was often necessary. She started saying that she would kill herself to escape the terror caused by what was happening. She started being aggressive and presenting the Capgras delusion. Since she was non-responsive to adequate dosage of two second-generation antipsychotics, standard titration of clozapine was initiated up to $250 \mathrm{mg}$ /day with ongoing monitoring in conformity with the current guidelines. Benzodiazepines were tapered off to discontinuation. The symptoms remitted in the next 5 days and the patient was discharged. After discharge, she continued the treatment for 6 months.

After 6 months the patient expressed the desire to switch from clozapine to olanzapine for several reasons: a) previous good outcome with olanzapine; b) less strict monitoring regimen; c) clozapine induced constipation. We chose the cross-tapering switch (6 weeks) in order to avoid rebound symptoms, based on our previous experience as well as the expert's opinion on this topic. ${ }^{18}$ The cross-tapering switch is presented in Figure 1.

Visit at 1 year after discharge revealed full remission of symptoms and a good level of functioning on $10 \mathrm{mg} /$ day olanzapine. We decided to gradually stop treatment with olanzapine during next 8 weeks. There were no signs of relapse at 6 months later. Family considered patient fully recovered.

\section{Discussions and Conclusions}

To our knowledge, PPP are very rarely treated with clozapine and data is limited on this topic. Most data are available from case reports and small studies. The term "resistant postpartum psychosis" is an analogy to the treatment-resistant schizophrenia, in which patients have persistent symptoms despite at least two adequate trials of neuroleptic drugs, over a prolonged period of time. ${ }^{18,19}$ In treatment-resistant schizophrenia clozapine is the gold standard. ${ }^{20}$

The risks for infants exposed to clozapine from breast milk are unknown. However, Imaz et $\mathrm{al}^{21}$ did not find any acute toxicological effect in the exposed newborns. Meanwhile, the majority of women stop breastfeeding during psychiatric hospitalization and therefore clozapine could be an alternative for the patients that are unresponsive to other antipsychotics. The treatment generally

\section{CLOZAPINE - OLANZAPINE}

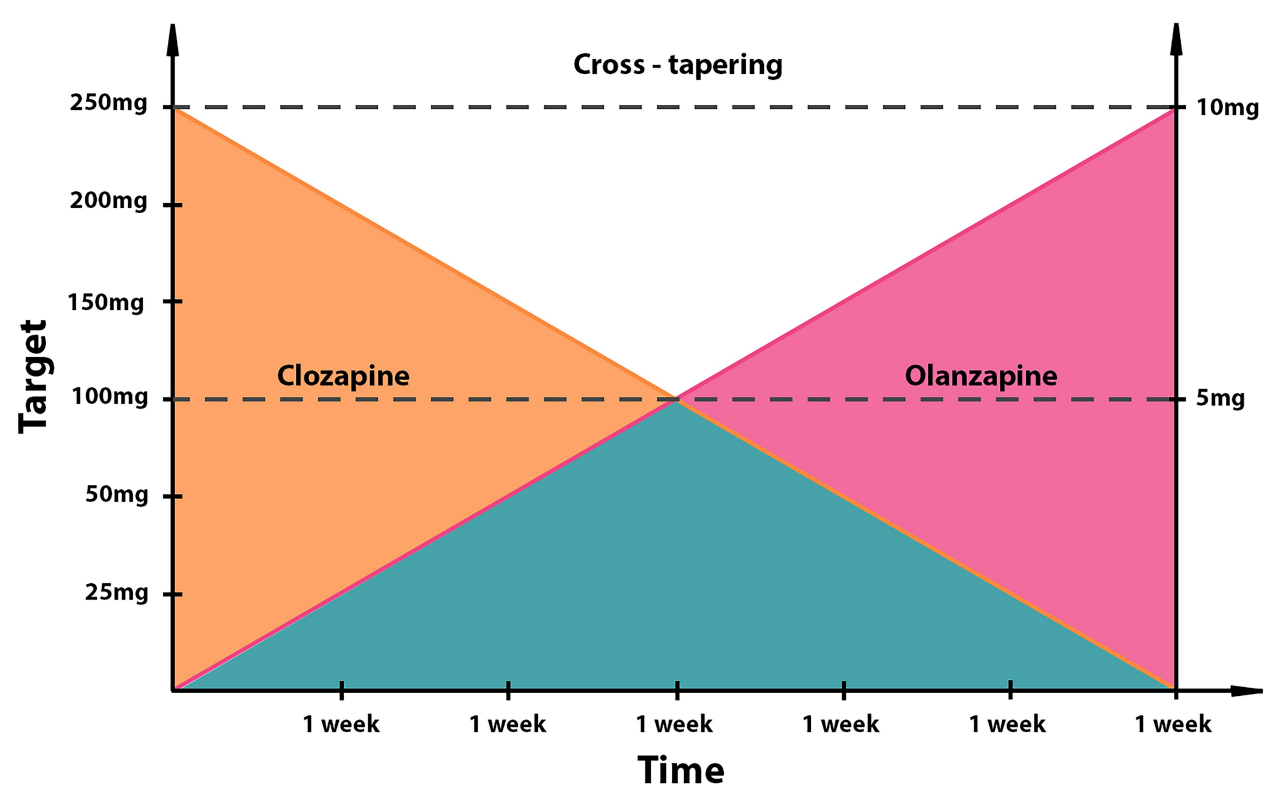

Figure I Clozapine to olanzapine cross-tapering. 
includes sequential administration of short-term benzodiazepines, antipsychotics, and lithium, with response monitoring. $^{22}$

Insufficient response to an antipsychotic is most often followed by changing the antipsychotic, which is associated with an increased risk of side effects, prolonged hospitalization and major psychological consequences for the patient and family. Cases of long-term treatmentresistant psychoses with onset during the postpartum period have been reported and a few studies have explored the efficacy of electroconvulsive therapy, but data sustaining the best therapeutic attitude for these cases is lacking. ${ }^{22,23}$

The recognition of treatment-resistant postpartum psychosis as a rare but severe condition will probably make the clinicians weigh clozapine as an efficient and safe treatment.

In Romania clozapine is indicated for TRS and psychosis in Alzheimer's Disease. According to our Hospital's protocols, we are allowed to use clozapine in patients with another psychiatric diseases in cases with severe agitation, aggressiveness, recurrent suicidal or selfmutilation behavior. This experience resulted from the numerous cases that needed to be resolved quickly in order to prevent prolonged mechanical restraint, loaded therapeutic regimens, prolonged hospitalization, etc. ${ }^{24}$

An important aspect of our report was the duration of antipsychotic treatment after discharge. Due to the high risk of relapse after postpartum psychosis, we considered necessary to continue the treatment for at least 1 year. ${ }^{25}$ A recent meta-analysis shows that more than $40 \%$ of women were classified as having "isolated postpartum psychosis" which could be considered a distinct diagnostic category. The remaining $60 \%$ of women had severe nonpuerperal psychotic episodes during longitudinal followup. $^{26,27}$

Although data is extremely limited, clozapine has been shown to be effective and safe in this severe case of treatment-resistant PPP. Further studies will show whether clozapine might be an option for all patients with treatment-resistant postpartum psychosis.

\section{Abbreviations}

PPP, Postpartum psychosis; DSM-5, Diagnostic and Statistical Manual of Mental Disorders, 5th edition; TRS, treatment-resistant schizophrenia; FGAs, First-generation antipsychotics; SGAs, Second-generation antipsychotics; CYPP450, Cytochrome P450; CYP1A2, Cytochrome P1A2; CYP3A4, Cytochrome P3A4.

\section{Data Sharing Statement}

Not applicable.

\section{Ethics Approval}

Not applicable.

\section{Consent for Publication}

The patient signed a voluntary written informed consent form authorizing the publication. A copy is available if requested.

\section{Author Contributions}

All authors made a significant contribution to the work reported, whether that is in the conception, study design, execution, acquisition of data, analysis and interpretation, or in all these areas; took part in drafting, revising or critically reviewing the article; gave final approval of the version to be published; have agreed on the journal to which the article has been submitted; and agree to be accountable for all aspects of the work. All authors read and approved the final manuscript.

\section{Funding}

There were no sources of funding.

\section{Disclosure}

All authors declare that they have no conflict of interests for this work.

\section{References}

1. Pfuhlmann B, Stoeber G, Beckmann H. Postpartum psychoses: prognosis, risk factors, and treatment. Curr Psychiatry Rep. 2002;4 (3):185-190. doi:10.1007/s11920-002-0025-6

2. Sutter AL, Bourgeois M. Complications émotionnelles et psychiatriques du post-partum [Emotional and psychiatric postpartum complications]. Contracept Fertil Sex. 1994;22(1):61-64.

3. Sit D, Rothschild AJ, Wisner KL. A review of postpartum psychosis. $J$ Womens Health. 2006;15(4):352-368. doi:10.1089/jwh.2006.15.352

4. Kemp B, Bongartz K, Rath W. Postpartale psychische Störungen - ein unterschätztes problem in der geburtshilfe [Psychic disturbances in the postpartum period: an increasing problem?]. Z Geburtshilfe Neonatol. 2003;207(5):159-165. doi:10.1055/s-2003-43419

5. American Psychiatric Association. DSM-5. Washington, DC: American Psychiatric Association; 2013:186-187.

6. González-Rodríguez A, Seeman MV. The association between hormones and antipsychotic use: a focus on postpartum and menopausal women. Ther Adv Psychopharmacol. 2019;9:2045125319859973. doi: $10.1177 / 2045125319859973$

7. Jones I, Hamshere M, Nangle JM, et al. Bipolar affective puerperal psychosis: genome-wide significant evidence for linkage to chromosome 16. Am J Psychiatry. 2007;164:1099-1104.

8. Kendell R, Chalmers J, Platz C. Epidemiology of puerperal psychoses. Br J Psychiatry. 1987;150.5.662. 
9. Harlow BL, Vitonis AF, Sparen P, Cnattingius S, Joffe H, Hultman CM. Incidence of hospitalization for postpartum psychotic and bipolar episodes in women with and without prior prepregnancy or prenatal psychiatric hospitalizations. Arch Gen Psychiatry. 2007;64(1):42-48. doi:10.1001/archpsyc.64.1.42

10. Friedman SH, Prakash C, Nagle-Yang S. Postpartum psychosis: protecting mother and infant. Curr Psychiatr. 2019;18(4):12-21.

11. Schöpf J, Rust B. Follow-up and family study of postpartum psychoses Part I: overview. Eur Arch Psychiatry Clin Neurosci. 1994;244:101-111. doi:10.1007/BF02193527

12. Nager A, Szulkin R, Johansson SE, Johansson LM, Sundquist K. High lifelong relapse rate of psychiatric disorders among women with postpartum psychosis. Nord J Psychiatry. 2013;67(1):53-58. doi:10.3109/08039488.2012.675590.

13. Sharma V. Pharmacotherapy of postpartum psychosis. Expert Opin Pharmacother. 2003;4(10):1651-1658. doi:10.1517/14656566.4.10.1651

14. da Silva L, Johnstone EC. A follow-up study of severe puerperal psychiatric illness. Br J Psychiatry. 1981;139:346-354. doi:10.1192/ bjp. 139.4 .346

15. Işı1k M. Postpartum psychosis. East J Med. 23(1).

16. Teodorescu A, Dima L, Popa MA, Moga MA, Bîgiu NF, Ifteni P. Antipsychotics in postpartum psychosis. Am J Ther. 2020;Publish Ahead of Print. doi: 10.1097/MJT.0000000000001218.

17. Teodorescu A, Ifteni P, Moga MA, Burtea V, Bigiu N. Dilemma of treating schizophrenia during pregnancy: a case series and a review of literature. BMC Psychiatry. 2017;17(1):311. doi:10.1186/s12888017-1475-Z

18. Green A, Stephenson T, Whiskey E, Shergill SS. Closure beyond clozapine: successfully averting rebound symptoms in a patient with schizoaffective disorder and agranulocytosis. BJPsych Open. 2019;5 (3):e43. doi:10.1192/bjo.2019.31

19. Raguraman J, Vijay Sagar KJ, Chandrasekaran R. Effectiveness of clozapine in treatment-resistant schizophrenia. Indian J Psychiatry. 2005;47(2):102-105. doi:10.4103/0019-5545.55955
20. Meltzer HY. Treatment-resistant schizophrenia - the role of clozapine. Curr Med Res Opin. 1997;14(1):1-20. doi:10.1185/ 03007999709113338

21. Weller M, Kornhuber J. Differentielle neurolepsie bei schizophrenen psychosen im wochenbett: vorteile des atypischen neuroleptikums clozapin [Differential neuroleptic treatment of schizophrenic psychoses in puerperium: advantages of the atypical neuroleptic clozapine]. Nervenarzt. 1992;63(7):440-441.

22. Imaz ML, Oriolo G, Torra M, Soy D, García-Esteve L, MartinSantos R. Clozapine use during pregnancy and lactation: a case-series report. Front Pharmacol. 2018;9:264.

23. Bergink V, Rasgon N, Wisner KL. Postpartum psychosis: madness, mania, and melancholia in motherhood. Am J Psychiatry. 2016;173 (12):1179-1188. doi:10.1176/appi.ajp.2016.16040454

24. Rapinesi C, Kotzalidis GD, Del Casale A, et al. Treatment-resistant, five-year long, postpartum-onset Capgras episode resolving after electroconvulsive therapy. Int $J$ Psychiatry Med. 2015;49 (3):227-234. doi:10.1177/0091217415582193

25. Andreea T, Petru I, Miron AA, et al. Clozapine for treatment-refractory aggressive behavior. Psychiatr Q. 2020. doi:10.1007/s11126-020-09839-x

26. Kapfhammer HP, Reininghaus EZ, Fitz W, Lange P. Clinical course of illness in women with early onset puerperal psychosis: a 12-year follow-up study. $J$ Clin Psychiatry. 2014;75(10):1096-1104. doi: $10.4088 / \mathrm{JCP} .13 \mathrm{~m} 08769$

27. Gilden J, Kamperman AM, Munk-Olsen T, Hoogendijk WJG, Kushner SA, Bergink V. Long-term outcomes of postpartum psychosis: a systematic review and meta-analysis. J Clin Psychiatry. 2020;81(2):19r12906. doi:10.4088/JCP.19r12906
Risk Management and Healthcare Policy

\section{Publish your work in this journal}

Risk Management and Healthcare Policy is an international, peerreviewed, open access journal focusing on all aspects of public health, policy, and preventative measures to promote good health and improve morbidity and mortality in the population. The journal welcomes submitted papers covering original research, basic science, clinical \& epidemiological studies, reviews and evaluations, guidelines, expert opinion and commentary, case reports and extended reports. The manuscript management system is completely online and includes a very quick and fair peer-review system, which is all easy to use. Visit http://www.dovepress.com/testimonials.php to read real quotes from published authors. 